\title{
James Madison y la expansión territorial, 1780-1790
}

Victor A. Arriaga

CIDE

El autor analiza, dentro del marco de la discusión sobre el federalismo, las tesis de James Madison en relación con la expansión territorial estadunidense.

INTRODUCCIÓN

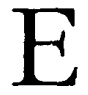

1 proceso de expansión territorial hacia tierras del occidente a lo largo de la historia de Estados Unidos, fue un proceso complejo que abarcó diversas fases. Este movimiento implicó la ocupación física y demográfica de nuevas tierras por parte de los norteamericanos, el establecimiento de instituciones políticas y sociales afines al modelo republicano estadunidense, la integración de regiones enteras a la economía capitalista y la incorporación de territorios extensos a la jurisdicción del gobierno central para su eventual transformación en entidades federativas.
De hecho, la expansión territorial antecede a la formación del Estado nacional norteamericano. Durante el periodo de gobierno inglés, hubo migraciones de colonos más allá de la cadena montañosa de los Apalaches, la frontera natural de las trece colonias. Al firmarse la paz entre la Gran Bretaña y Estados Unidos en 1783, la corona inglesa transfirió una gran extensión de territorio ubicado entre los Apalaches y la margen oriental del río Mississippi a la joven república. Este inmenso territorio atrajo a miles de ciudadanos norteamericanos, tanto especuladores de tierras como agricultores, y creó presiones sobre los gobiernos estatales y el nacional 
para definir el estatus de estas tierras dentro de la república. A la vez, la contigüidad territorial de Estados Unidos con España, la potencia colonial europea con dominios a lo largo del continente america no y en aquellos años soberana de la Florida, el vasto territorio de la Luisiana y, de particular interés, del estratégico puerto de Nueva Orleans, provocó problemas diplomáticos debido a controversias sobre los limites y al interés de los norteamericanos en garantizar su acceso a la desembocadura del río Mississippi.

El objetivo de este artículo consiste en analizar tres facetas de la expansión norteamericana entre 1780 y 1790 , el periodo de conformación del Estado nacional estadunidense. El examen de la incorporación de nuevas tierras a la unión, la discusión de los derechos de navegación en el río Mississippi y el debate en torno al tamaño ideal de la república, permitirán conocer algunos de los rasgos principales de la expansión en el último cuarto del siglo xviri. De particular interés será abordar el análisis de la relación entre la expansión y el republicanismo y el pensamiento sobre este aspecto de James Madison, uno de los principales artífices de las instituciones que todavía perduran hasta nuestros dias.

Entre los historiadores norteamericanos, el republicanismo ha sido identificado como una de las corrientes intelectuales e ideológicas que influyeron en la formación de las instituciones políticas nacionales y que eran parte del discurso político de la época, ${ }^{1}$ pero pocos autores

\footnotetext{
${ }^{1}$ Algunos ejemplos de esta corriente son: Bailyn, Ideological, 1967; Pocock, Machiavellian, 1975; Ross, "Liberal", 1979, pp. 116-131; Wood, Creation,1969. La corriente republicana surge como una respuesta a las tesis del predominio del liberalismo en el pensamiento político nortea-
}

han abordado en forma sistemática el estudio de la relación entre los principios del republicanismo y el tema de la expansión territorial. Este artículo examinará esta relación pues durante este periodo surgieron distintas nociones sobre el republicanismo, las instituciones republicanas y, más importante aún, el impacto de la expansión territorial en el carácter de la república. Los debates de la época y el análisis de Madison revelan que la expansión y el tamaño de la república formaban parte de los temas relevantes de la discusión política.

La expansión tenía una dimensión estratégica pues era un medio para colocar puntos de importancia geográfica bajo la jurisdicción de Estados Unidos. Además, con el fin de las regulaciones mercantilistas del imperio colonial inglés, la incorporación de nuevas tierras permitiría a la agricultura estadunidense adquirir un nuevo impulso y orientarse hacia una explotación comercial intensa, contribuyendo decisivamente al desarrollo de la economía capitalista norteamericana. Por otro lado, la expansión estaba relacionada con un esquema más amplio, el del proyecto político nacional. Así, James Madison defendió la noción de una república extensa que crecía a través del tiempo y del espacio como un medio para lograr la adecuada representación de intereses diversos en el Congreso.

Esta revisión proporcionará una visión más amplia del complejo proceso de expansión territorial durante los años de la fundación de la república, pues al crecer en territorio, la adhesión a los

mericano planteadas por Hartz, Liberal, 1955. A su vez, la corriente revisionista ha sido duramente cuestionada por autores como Appleby, "Republicanism" 1986, pp. 20-34 y Kramnick, "Republican", 1982, pp. 629-664. 
principios republicanos se manifestó en circunstancias y situaciones diversas, revelando a la vez las particularidades de la expansión en este periodo decisivo de la historia norteamericana.

LAS TIERRAS DEL OESTE Y LA EXPANSIÓN DEL REPUBLICANISMO

Durante el periodo colonial, las cédulas reales de Virginia, Georgia, Massachussetts, Connecticut, Carolina del Norte y del Sur reconocian la jurisdicción de estas colonias sobre grandes extensiones de territorio en el oeste. En algunos casos, las pretensiones territoriales abarcaban porciones de tierra que llegaban a las costas del océano Pacífico, aun cuando en realidad sólo había asentamientos en la región de los Apalaches y en el valle del río Ohio.
Durante la guerra de independencia estas entidades mantuvieron sus reclamos territoriales pero, al hacerlo, surgieron serios problemas para la nueva nación, pues los estados sin derechos territoriales exigieron la anulación de dichas reclamaciones. Por otro lado, la especulación con tierras en la parte occidental de la nación se incrementaba a pesar de que no había certeza de que las transacciones fueran a tener valor legal en el futuro. El debate sobre las tierras del oeste generó tensiones entre los estados, entre el gobierno nacional y los estados, y entre los especuladores y los estados con reclamos territoriales. En 1779 Maryland se negó a ratificar los Artículos de la Confederación, el primer texto constitucional de Estados Unidos, hasta que los otros estados renunciaran a sus reclamos.

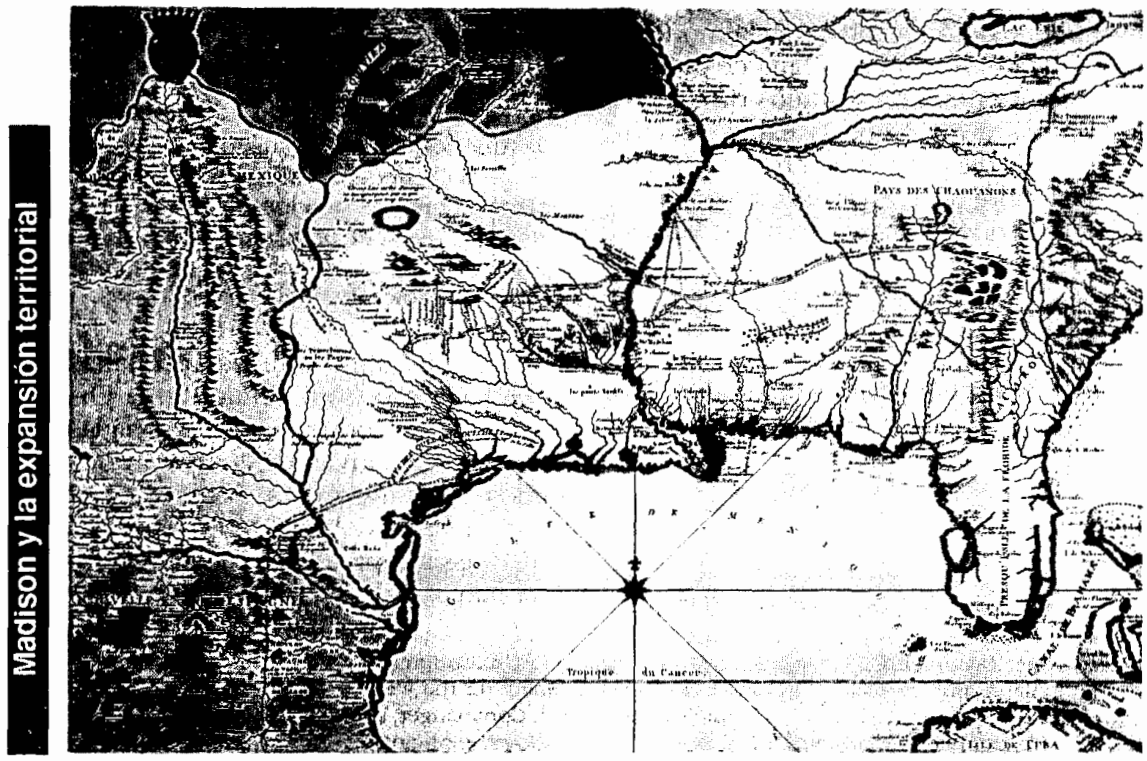


A lo largo de las controversias sobre el futuro de los territorios del oeste al discutirse su estatus, los políticos de la época hacian constantemente referencia a la forma de gobierno republicana. En su primera resolución sobre tierras públicas, el Congreso Continental recomendó a los estados con reclamaciones ceder los territorios al gobierno nacional, y determinó que cualquier superficie sin propietario que los estados cedieran al gobierno

será poblada y conformará estados republicanos claramente definidos que serán miembros de la unión federal y tendrán los mismos derechos a la soberanía, libertad e independencia que tienen los demás estados. $^{2}$

Al tener la mayor cantidad de títulos válidos y las pretensiones territoriales más extensas, el gobierno estatal de Virginia recibió presiones muy intensas hasta que cedió los territorios al norte y poniente del río Ohio. La falta de definición del estatus de los títulos de tierras adquiridas a través de la especulación postergóla decisión, pero en la ley del 20 de diciembre de 1783 la asamblea general del estado finalmente cedió las tierras occidentales bajo

la condición de que el territorio cedido deberá distribuirse para integrar estados con una extensión territorial adecuada [...] y los estados que así se formen serán estados republicanos claramente definidos. ${ }^{3}$

2 EUA, Congreso Continental, "Resolution of Congress on public lands", 10 de octubre de 1780 , Commanger, Documents, 1973; p. 120.

${ }^{3}$ Virginia, Asamblea Estatal, "Virginia's cession of western land to the United States", 20 de diciembre de 1783, Commanger, Documents, 1973, p. 121.
La controversia sobre los territorios del oeste se resolvió parcialmente en 1784, poco después de que la Gran Bretaña reconoció la independencia de Estados Unidos. El Congreso Continental adoptó un plan de gobierno para estos territorios el 23 de abril de 1784. Thomas Jefferson fue el autor principal de este proyecto que una vez más revelaba la profunda preocupación por el tipo de gobierno adecuado para los territorios. El plan confirmaba que "el territorio que las entidades individuales vayan a ceder o hayan cedido [...] será dividido en estados claramente definidos". Los pobladores de los territorios tenían derecho a establecer un gobierno temporal y una vez cubiertas ciertas condiciones podían adquirir un gobierno permanente mediante un congreso constituyente, convirtiéndose así en estados de la unión. Los gobiernos, tanto temporales como permanentes, debían establecerse de acuerdo con los siguientes principios:

1. Quedarán integrados permanentemente a la confederación de los Estados Unidos de América. 2. Estarán sujetos a los artículos de la Confederación en todos aquellos casos en que lo estén los estados originales [...] 4. Estarán obligados a pagar una parte de la deuda federal [...] 5. Sus respectivos gobiernos serán republicanos. ${ }^{4}$

Una de las últimas leyes aprobadas por el Congreso Continental fue la Ordenanza del Noroeste que establecía las bases administrativas de los territorios cedidos por Virginia, es decir, la zona ubicada al norte del río Ohio y al oriente del rio Mississippi. La ordenanza mantenía la mayoría de las estipulaciones del

4 EUA, Congreso Continental, "Report of government for the western territory", 23 de abril de 1784 , Commanger, Documents, 1973, p. 122. Subrayado en el original. 


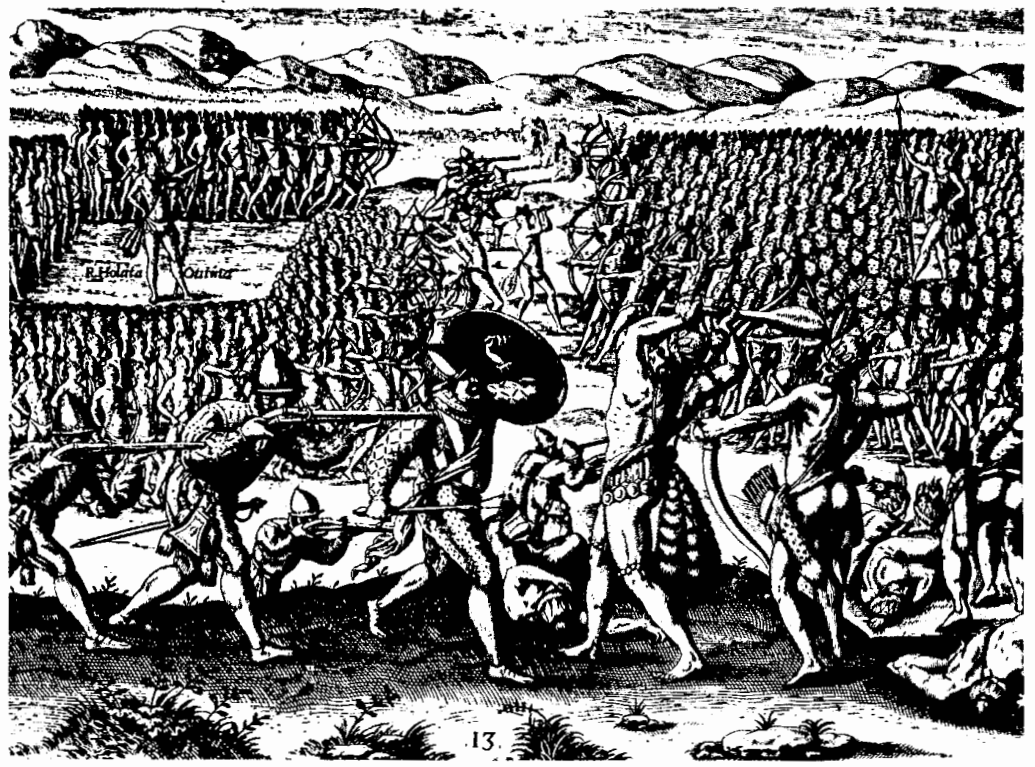

reporte de 1784 . Además definía las funciones de los administradores nombrados por el gobierno nacional, las asambleas generales, los jueces y los derechos legales y religiosos de los habitantes. Por último, estipulaba que la admisión de los futuros territorios como estados sería "en condiciones de igualdad a los estados originales en todos los aspectos". Una de las condiciones explícitas para acceder a la categoría de entidad federal era el compromiso con el republicanismo pues los futuros estados tenían "la libertad de establecer una constitución y un gobierno permanente, siempre y cuando la constitución así creada [fuera] republicana".

Esta revisión revela el compromiso claro con el republicanismo como for-

SEUA, Congreso Continental, "The northwestern ordinance", 13 de julio de 1787 , Commanger, Documents, 1973, pp. 131-132. ma de gobierno y de organización política para los nuevos territorios, pues los fundadores expresaron su adhesión a las formas republicanas no sólo para las instituciones nacionales y estatales sino también para los territorios del oeste ya que debían cubrir ciertos requisitos y la aceptación del republicanismo era clave. Los territorios serían regidos por gobiernos de principios republicanos -en contraposición a cualquier forma de régimen colonial-y los futuros estados debían organizarse bajo los ideales republicanos. Los estados que entregaron tierras al gobierno federal lo hicieron con la condición de que las nuevas entidades se organizarían bajo los principios republicanos. El gobierno nacional, en este caso el Congreso Continental, también fijó las reglas para los futuros estados, haciéndolo bajo el principio de igualdad pues se admitirían bajo las mis- 
mas circunstancias que los trece estados originales.

Así, en esta fase inicial de la expansión hacia el oeste, las tierras bajo la soberanía de Estados Unidos y de los estados con pretensiones territoriales quedaron organizadas bajo los principios del republicanismo, una forma de gobierno concebida como adecuada no sólo para los estados originales sino también para los nuevos miembros de la unión. En esta fase, el crecimiento de la base territorial de la nación y la expansión del republicanismo fueron movimientos simultáneos.

MADISON Y LA CONTROVERSIA SOBRE LOS DERECHOS DE NAVEGACIÓN EN EL RÍO MISSISSIPPI

Durante el periodo colonial numerosos colonos y pobladores avanzaron de la costa a las regiones más allá de los Apalaches y se asentaron en el valle del río Ohio y en las tierras que ocupan los estados de Kentucky, Tennessee y Alabama, iniciando asíla explotación de productos agrícolas en forma extensiva. Algunos territorios estaban bajo el dominio británico y otros bajo el gobierno colonial español. La soberanía sobre la tierra localizada entre Florida y Luisiana no estaba totalmente definida y en algunos casos había controversias en torno a sus límites. CuandoGran Bretaña reconoció la independencia norteamericana mediante el tratado de paz de París en 1783, Estados Unidos adquirió todos los territorios que habían estado bajo dominio británico y el movimiento demográfico hacia las tierras del oeste continuó.

La controversia sobre los derechos de navegación en el río Mississippi entre Estados Unidos y España sacó a la luz algunos de los principios relacionados con el republicanismo y las justificaciones teóricas de los norteamericanos para incorporar nuevas tierras.

El problema surgió cuando la corona española intentó impedir el derecho a la navegación por el río Mississippi a barcos de otras naciones. En repetidas ocasiones los pobladores norteamericanos asentados en la margen oriental del tío intentaron presionar a su gobierno nacional para que negociara un tratado con España que resolviera este problema sobre la base de la defensa del libre tránsito de barcos y bienes a lo largo del Mississippi. El asunto de la libre navegación era un elemento central de las relaciones norteamericanas con España. Al controlar la corte de Madrid la desembocadura del río Mississippi y los territorios al occidente de esa vía fluvial, continuamente buscó ejercer la exclusividad de la navegación.

Durante la guerra de independencia, además de obtener el apoyo de Francia, los norteamericanos solicitaron ayuda externa y buscaron el apoyo de otras naciones. El Congreso Continental designó a John Jay para negociar el apoyo español. España exigió la exclusividad de derechos de navegación a cambio de su ayuda, pero no tuvo éxito en su petición. Después de la firma del tratado de paz con la Gran Bretaña, el gobierno estadunidense buscó firmar acuerdos comerciales con las naciones europeas y al acercarse a la corona española en 1785 resurgió el tema de la exclusividad de los derechos de navegación, al pugnar la corte de Madrid por el cierre a la navegación extranjera durante 25 años.

En ambas ocasiones la propuesta española creó una profunda división dentro de Estados Unidos. Los intereses comerciales de la costa atlántica, centrados en Nueva Inglaterra y Carolina del Sur, se mostraban dispuestos a aceptar la petición española. Los representantes de Vir- 
ginia y Carolina del Norte -estados eminentemente agrícolas que entonces incluían tierras recién abiertas a cultivos al este del río Mississippi- se oponían sistemáticamente a tales reclamos. En 1785 el Congreso Continental llegó a discutir una propuesta de tratado con España que contemplaba la exclusión de derechos de navegación por 25 años. La división regional quedó abiertamente manifiesta durante los debates.

A lo largo de este periodo, James Madison continuamente defendió la libre navegación. Ya desde 1780 Madison, entonces miembro del Congreso Continental, expuso su postura respecto a los derechos de navegación en una carta dirigida a John Jay que contenía instrucciones para las negociaciones con España. En esta carta Madison argumentaba que, como resultado del tratado de París de 1763 entre España y la Gran Bretaña, "todo el territorio ahora reclamado por Estados Unidos fue cedido expresa e irrevocablemente al rey de Gran Bretaña". Como consecuencia de la guerra de independencia, consideraba que Estados Unidos "tenía derecho a los beneficios de dicha cesión".

Como resultado de la independencia, los derechos soberanos, incluyendo el uso benéfico del territorio, recaían de nuevo en manos del pueblo norteamericano. La postura de Madison enfatizaba la importancia del beneficio y del uso benéfico de la tierra como un elemento para justificar un título de soberanía sobre el territorio. Ya desde 1780 Madison también hacía hincapié en la relación entre el uso benéfico del territorio y la libre navegación por el Mississippi:

En vista de que Estados Unidos tiene el indisputable derecho de posesión de la

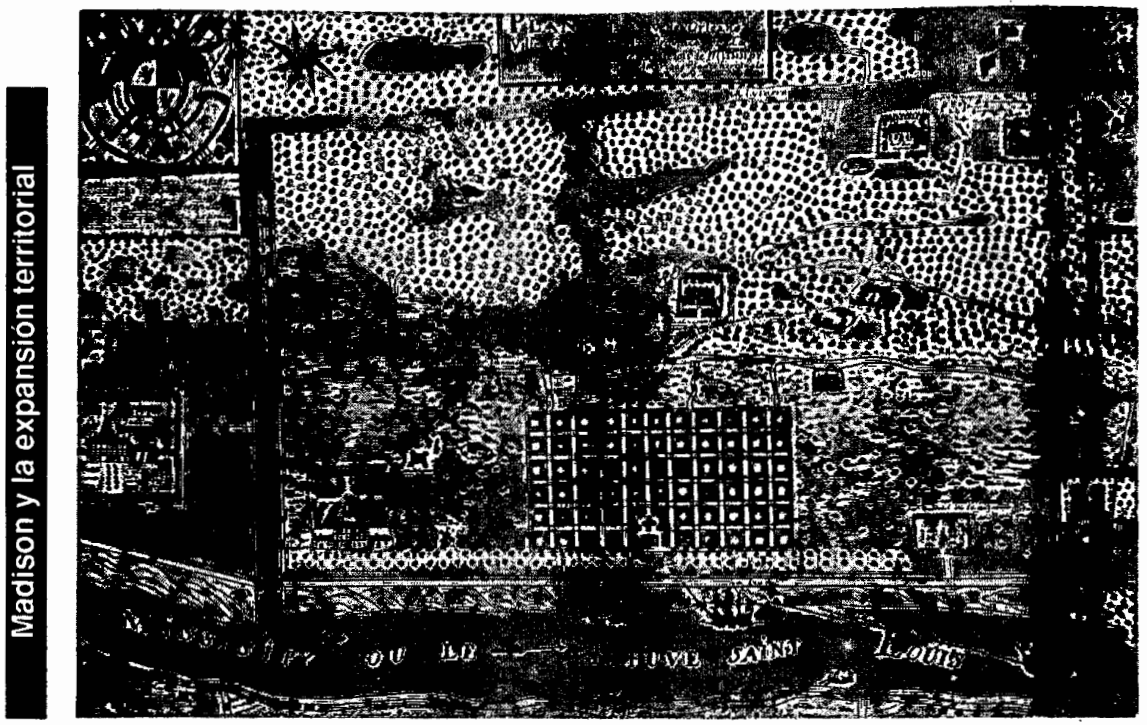


ribera oriental del río Mississippi a lo largo de una gran extensión, y la navegación por el río acarreará esencialmente la prosperidad y ventajas a los ciudadanos de Estados Unidos establecidos en las riberas del Mississippi o en las aguas que desembocan en él, queda concebida [a pesar de] la circunstancia de que España esté en posesión de ambas riberas cerca de su desembocadura no puede considerarse ni justa ni natural la exclusión para el libre uso del río. Tal principio autorizaría a una nación dispuesta a tomar ventaja de las circunstancias para contravenir las claras indicaciones de la naturaleza y providencia y el bien general de la humanidad. ${ }^{6}$

De esta manera, Madison sostenía que la postura de España sobre la pretendida exclusividad de los derechos de navegación en el Mississippi atentaba contra la naturaleza y el beneficio de la humanidad pues argumentaba queel desarrollo de la agricultura por parte de los pobladores norteamericanos en las tierras al este del río era benéfico para todas las naciones, por lo cual la libre navegación era necesaria para comercializar la producción excedente. ${ }^{7}$

En una carta dirigida a Thomas Jefferson después de la firma del tratado de paz de 1783, James Madison escribió acerca de los beneficios que acarrearía la independencia a la agricultura y comercio norteamericanos. Al desarrollar este tema se refirió a la expansión de la agricultura en el oeste y al incremento en los precios de los productos agrícolas norte-

\footnotetext{
${ }^{6}$ James Madison a John Jay, "Draft explaining his instructions", 17 de octubre de 1780, Madison, The Papers, 1962, t. H, p. 132.

7 La influencia del jurista suizo Emmerich de Vattel, autor de Droit de gens, sobre este punto es clara. Vattel sostenía que era necesario hacer uso de tierras potencialmente productivas para beneficiar a la humanidad.
}

americanos, y luego se quejó de la política del gobierno español de evitar el uso del río Mississippi, lo cual representaba un obstáculo para el comercio norteamericano. En 1784 la visión de Madison acerca del problema global era optimista, pues sentía que España no podía detener la expansión del comercio norteamericano, y argumentaba que la naturaleza estaba de parte de Estados Unidos:

Nada puede retrasar una revolución tal con respecto a nuestro principio salvo un intento imprudente y perverso de España de cerrar la desembocadura del Mississippi en contra de los habitantes [arriba mencionados]. Digo retrasar porque [España] no puede parar definitivamente el flujo comercial por el río, como tampoco puede detener la corriente misma [del ríol. ${ }^{8}$

La carta contenía un detallado examen de los diferentes factores que harian a España cambiar su política. La percepción de Madison acerca del poderio norteamericano merece especial atención por su relación con otros aspectos de su pensamiento político y con el tema del republicanismo norteamericano. Ya desde 1784 Madison consideraba que Estados Unidos era una potencia que podía afectar el equilibrio regional y que España, en esos momentos soberana de grandes extensiones en el hemisferio occidental, necesitaba desarrollar relaciones pacíficas con Estados Unidos para poder mantener sus posesiones:

Estados Unidos ya es una potencia que no debe ser menospreciada por España; no está lejano el día cuando, a pesar de todas las precauciones, la seguridad de sus po-

${ }^{8}$ Madison a Thomas Jefferson, 20 de agosto de 1784, Madison, Letters, 1865, t. I, p. 93. 
sesiones [de España] en esta parte del globo deba depender más de nuestras relaciones pacíficas que de su poderio. ${ }^{9}$

La percepción de Madison acerca del poderío norteamericano lo llevó a creer que había suficientes razones que presionarían a España para llegar a un acuerdo. Continuaba su argumento con un análisis sobre la seguridad de España y la expansión de Estados Unidos. Estaba convencido de que una república más amplia ofrecería a la corte de Madrid seguridad permanente. En su argumento presentó algunas ideas acerca de la república extensa, que desarrolló ampliamente en el décimo ensayo federalista, ${ }^{10}$ aunque en la carta a Thomas Jefferson

\footnotetext{
9 Ibid., t. I, p. 94.

10 Este punto se desarrolla en el siguiente
} apartado. orientó los argumentos hacia los beneficios que otras naciones podrían derivar de una república extensa. Madison escribió que

la seguridad permanente [de España] parece descansar en la complejidad de nuestro gobierno federal y en la diversidad de intereses entre sus miembros. Como resultado de su complejidad es improbable que se tomen medidas ofensivas en un consejo y sería difícil ejecutarlas. Si tal fuera el caso, cuando trece estados integran el sistema, ¿no desearía ella ver el número aumentado a $23 ?^{11}$

Madison presentó sus ideas más elaboradas sobre el tema de la libre navegación en una carta dirigida al marqués

${ }^{11}$ Madison a Jefferson, 20 de agosto de 1784 , Madison, Letters, 1865, t. I, p. 94.

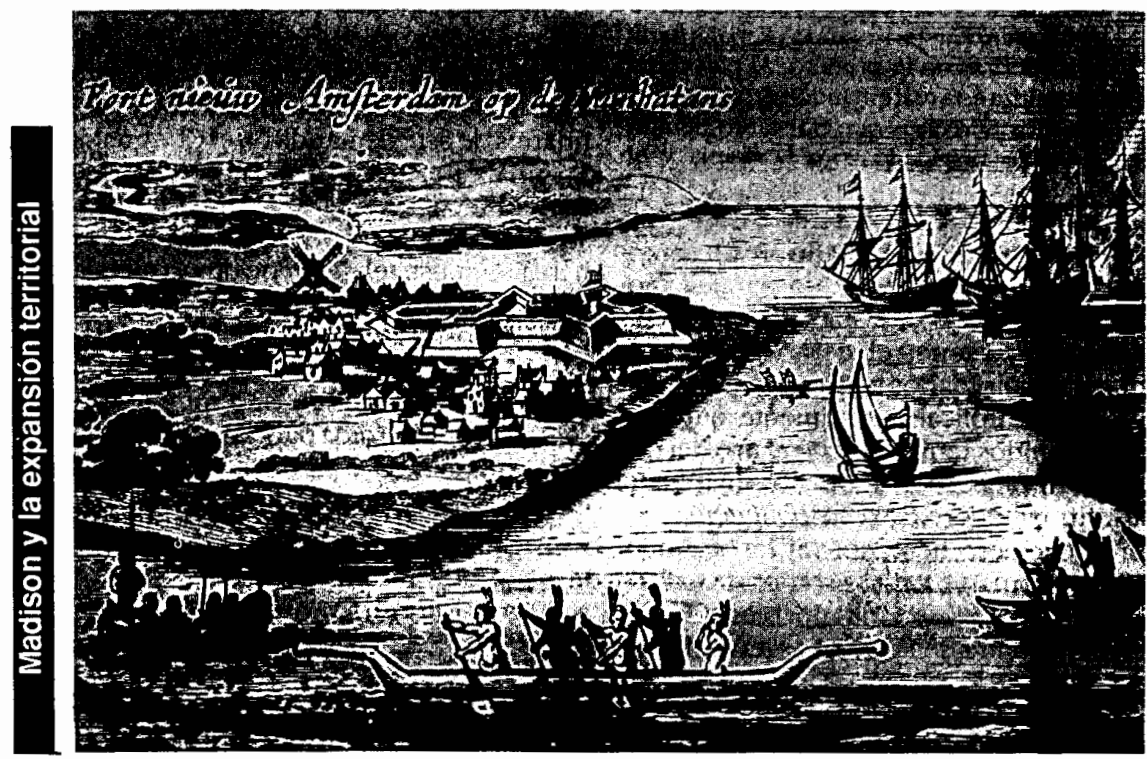


de La Fayette, escrita en marzo de 1785. El tono de esta carta refleja el creciente sentimiento de frustración de Madison porque España continuaba presionando para conservar la exclusividad de los derechos de navegación en el Mississippi. En su análisis afirmaba que la navegación era vital para el desarrollo económico de la parte occidental de Estados Unidos. Estaba convencido que el "valor de esa vasta extensión de territorio" dependía de la libre navegación por el Mississippi. Continuaba su presentación con una comparación entre los derechos a la independencia y la navegación otorgados por la naturaleza:

La naturaleza ha otorgado el uso del Mississippi a aquellos que se establezcan a las orillas de sus aguas, como dio a Estados Unidos [el derecho] a su independencia. La política de España puede retrasar lo primero como la Gran Bretaña retrasó lo segundo. Pero así como Gran Bretaña no podia derrotar lo segundo, España tampoco podrá con lo primero. Al parecer la naturaleza está reafirmandoen todas partes aquellos derechos que por tanto tiempo han sido pisoteados por la tiranía y el fanatismo. ${ }^{12}$

Por consiguiente, Madison presentó su argumento haciendo un paralelismo entre los deseos de España y Gran Bretaña para detener el desarrollo de los derechos otorgados por la naturaleza. Su posición implicaba claramente que Estados Unidos tenía derecho al uso del río Mississippi, pero en la carta fue más lejos al afirmar que existía la obligación de promover ese derecho: "Si los Estados Unidos toman partido en la obstrucción del Mississippi, serían culpables de traición en contra de las mismas leyes de las

\footnotetext{
${ }^{12}$ Madison al marqués de La Fayette, 20 de marzo de 1785, ibid., t. I, p. 137.
}

cuales obtienen y sostienen su existencia natural. ${ }^{13}$

Madison continuaba su análisis con un ataque a la política española que evitaba el uso adecuado de la tierra que rodea al Mississippi, ya fuera impidiendo un completo desarrollo agrícola oel libre comercio de los excedentes de la producción agrícola. ${ }^{14} \mathrm{El}$ ataque de Madison señalaba que

un extenso desierto parece tener mayores encantos ante sus ojos que un imperio floreciente perolimitado $(. .$.$) La humanidad$ no puede suprimir el deseo de que algunos de esos dones de los que abusa fueran puestos por justos medios en manos de aquellos que les dieran un uso más sabio. ${ }^{15}$

Pero la presión dentro de Estados Unidos para lograr un acuerdo comercial con España revelaba que había ciertos intereses dispuestos a aceptar las demandas españolas. Madison estuvo en contra de la propuesta de la corte de Madrid de 1785 y atacó a los norteamericanos partidarios de esta demanda en el Congreso. En una carta dirigida a James Monroe atacó directamente a España y presentó sus fundamentos teóricos. La naturaleza había impuesto el deber de desarrollar la tierra cercana al Mississippi; por consiguiente los intentos de cerrar la navegación tendrían como resultado la depreciación del valor de la tierra y representaríanuna pérdida para la humanidad. Madison planteó la siguiente pregunta:

\footnotetext{
13 Ibid.

${ }^{14}$ Por lo tanto, de nueva cuenta sus argumentos tenían alguna similitud conla posición de Emmerich de Vattel sobre la necesidad de cultivar la tierra en beneficio de la humanidad.

${ }^{15}$ Madison a La Fayette 20 de marzo de 1785 , Madison, Letters, 1865, t. I, p. 137.
} 
¿Puede haber una política más miope y poco honorable que estar de acuerdo con España para frustrar la benevolencia de la naturaleza, de vender los afectos de nuestros hermanos ultramontanos, de despreciar el fondo más rico que poseemos $[. .$.$] ? { }^{16}$

Madison temía que la cesión de los derechos de navegación tendría implicacion'es negativas en el movimiento para incrementar las atribuciones del gobierno nacional pues este debate ocurrió al mismo tiempo en que diferentes fuerzas intentaban convocar una reunión para reformar los artículos de la Confederación. Alllegar a una acuerdo para reunirse en Filadelfia y discutir la aprobación de un nuevo texto constitucional, James Madison le escribió a George Washington para informarle de los efectos contrarios que el potencial acuerdo con España tendría sobre las fuerzas políticas en su estado natal, Virginia. En una carta enviada desde Richmond escribió:

estaba totalmente convencido por lo que observé ahí, que a menos de que el proyecto del Congreso pueda ser revocado, la esperanza de conducir a este estado a un sistema federal adecuado será demolida [...] El señor Henry, quien hasta ahora ha sido el campeón de la causa federal, se ha

\footnotetext{
${ }^{16}$ Madisona James Nionroe, 21 de junio de 1786 , ibid., Tomo 1, pp. 239-240. Durante ese mismo periodo, Thomas Jefferson presentó sus puntos de vista en relación con el tema y defendió la agricultura al indicar que promovía cierto tipo de ciudadania que era favorable a los regímenes republicanos pues sostuvo que "ahora tenemos tierras suficientes para dar empleo a un infinito número de gente en su cultivo. Los labradores de la tierra son los ciudadanos más valiosos. Son los más vigorosos, los más independientes, los más virtuosos y están ligados a su país y casados con su libertad e interés por medio de los lazos más perdurables." Ver Jefferson a Jay, 23 de agosto de 1785, Jefferson, Writings, 1944, pp. 530-531.
}

convertido en un frío defensor, y en caso de un sacrificio real del Mississippi por parte del Congreso, incuestionablemente se irá al otro bando. ${ }^{17}$

En junio de 1788 , durante los debates de ratificación de la nueva constitución en Virginia, los opositores hicieron referencia en varias ocasiones al hecho de que el Congreso Continental prácticamente había cedido los derechos de navegación. Madison estuvo de acuerdo en los ataques en contra de los partidarios de la cesión, pero hizo una defensa de la Constitución de 1787 que indicaba claramente una división de intereses a lo largo de las líneas seccionales y regionales. Incluso hasta afirmó que dentro del nuevo marco constitucional, el interés agrícola tendría una representación favorable y que sus derechos serían defendidos adecuadamente, pues al crecer el número de habitantes en las regiones agrícolas, su influencia política sería mayor. Bajo el nuevo marco constitucional

[1]a gente en general escoge a quienes elegirán al presidente. El peso de la población será una mayoría a favor de este derecho [a la libre navegación]. Como el presidente debe proceder influenciado por el sentido e interés de sus electores, hasta donde dependa de él (y su capacidad de negociar tratados es la misma que la del senado) se opondrá a la cesión de la navegación. Y en relación a la influencia de los representantes, también decidirán a favor de este derecho. ${ }^{18}$

\footnotetext{
${ }^{17}$ Madisona George Washington, 7 de diciembre de 1786, Madison, Letters, t. I, p. 264.

${ }^{18}$ Madison, "General defense of the Constitution: the Mississippi question", Madison, Papers, 1962 , t. xI, pp. 137-138.
} 

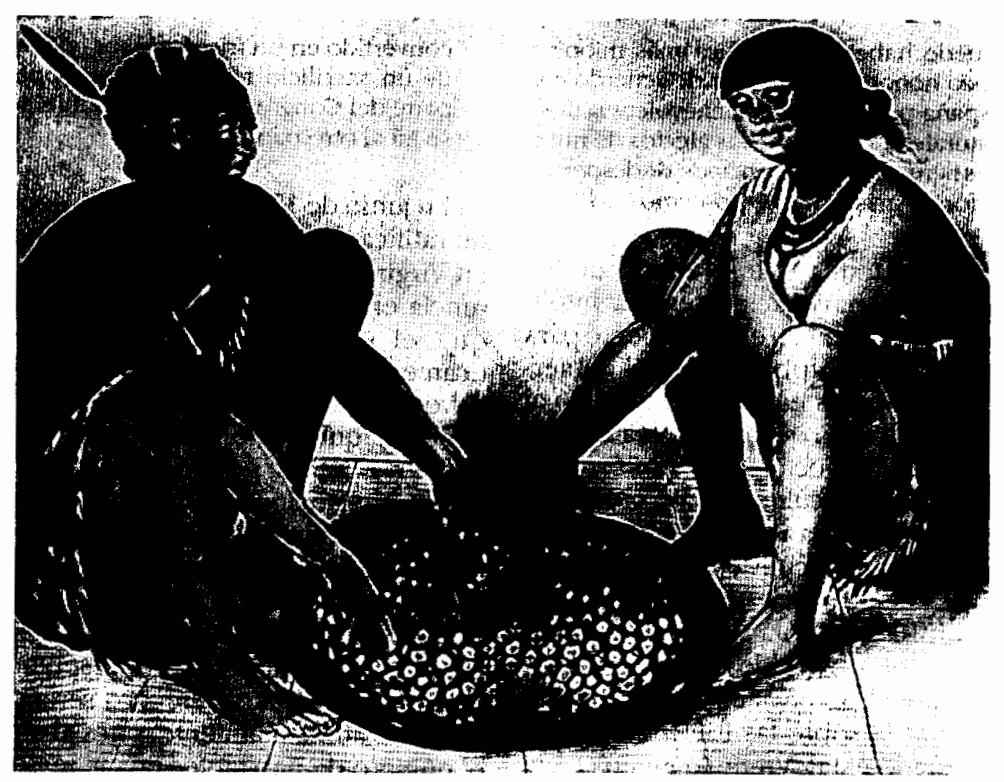

MADISON Y EL TAMAÑO IDEAL DE LA REPÚBLICA

Uno de los principales debates dentro del pensamiento republicano norteamericano giró en torno al tamaño ideal de la república. Diferentes teóricos europeos del republicanismo habían analizadoeste problema. En los Discursos, Maquiavelo reconoció la posibilidad de que bajo ciertas condiciones una república podía crecer y a la vez mantener sus virtudes y poderío. En su ensayo sobre la "Idea de una comunidad perfecta", Hume relacionó el principio de representación de intereses diversos con las mejores formas de gobierno. Para este autor, una república de amplias dimensiones territoriales era viable siempre y cuando hubiera ciertos arreglos institucionales; uno de los beneficios de la extensión era la crea- ción de intereses diversos sin que hubiera uno que dominara a todos los demás. En El espiritu de las leyes, Montesquieu, por el contrario, sostenía que la forma de gobierno republicana sólo era posible para comunidades pequeñas, pues el crecimiento garantizaba la aparición de tendencias tiránicas entre los gobernantes y la difusión del sentido de identidad común entre los habitantes; al crecer, los ciudadanos perdían las virtudes esenciales para el mantenimiento de la república. Los principales pensadores norteamericanos conocían estos argumentos y lós utilizaron al discutir el tema del tamaño ideal de la república.

De hecho, uno de los principales argumentos de los opositores a la Constitución de 1787 -los llamados antifederalistas-, al darse los debates de la ratificación de ese texto, fue la imposibilidad 
de mantener un gobierno republicano en un territorio tan extendido como el norteamericano. Según ellos, esta forma de gobierno sólo era posible para comunidades pequeñas con una población reducida y homogénea. Sólo una república pequeña podía garantizar la adhesión de la población, asegurar el quehacer gubernamental al pueblo y generar el tipo de ciudadanía y de virtudes cívicas necesarias para mantener una forma de gobierno republicana. ${ }^{19}$

Por su parte, una de las principales tareas de los defensores de la Constitución, los llamados federalistas, fue invalidar la creencia de que la república sólo era viable en un territorio reducido. James Madison se encargó de refutar los argumentos a favor de la república pequeña al relacionar el principio de la representación, como se verá más adelante el elemento central del republicanismo norteamericano, con la extensión territorial. Dentrodel esquema federalista, en una república extensa los mejores pasarían a ocupar los cargos de representación. En lugar de basarse en una ciudadanía homogénea, virtuosa y dispuesta a sacrificar sus intereses individuales por el bien común, como lo sostenía el pensamiento republicano clásico, en el modelo de los federalistas el territorio inmenso ofrecía oportunidades para todos los ciudadanos de satisfacer sus intereses individuales a través del acceso a la propiedad y la participación en la agricultura comercial. Al diversificarse los intereses en la república, el riesgo de la creación de una mayoría tiránica sobre una minoría desprotegida se anulaba y se seleccionaba a los mejores para ejercer los cargos de representación. ${ }^{20}$

\footnotetext{
${ }^{19}$ Storing, What, 1981, p.16.

${ }^{20}$ Ibid., p. 41.
}

Los antifederalistas plantearon sus argumentos en diversos documentos anónimos. A.los pocos días de la aprobación del texto constitucional en Filadelfia, el "Centinela" advertía que no sería difícil probar que sólo el despotismo podía mantener unida a una república tan grande como la norteamericana. ${ }^{21}$ En sus cartas "Bruto" se preguntó si era posible establecer un gobierno republicano en un país tan extenso como Estados Unidos. Este autor planteaba que "si se va a respetar la opinión de los hombres más grandes y sabios que han pensado o escrito sobre la ciencia del gobierno, debemos limitarnos a concluir que una república libre no puede tener éxito en un país de tales dimensiones". 22 "Bruto" identificó explícitamente a Montesquieu entre los pensadores que analizaron este punto y argumentó que "la historia no ha dado ningún ejemplo de una república libre comparable al tamaño de Estados Unidos. Las repúblicas griegas eran pequeñas y también lo fueron las romanas." En las repúblicas extensas, el crecimiento y la conquista habían provocado la corrupción de los principios republicanos; al expandirse, "sus gobiernos cambiaron de gobiernos libres a los más tiránicos que hayan existido en el mundo"..3

Además del temor a la tiranía, los antifederalistas estaban preocupados por el tamaño de la república porque esta forma de gobierno se basaba en el sufragio popular y para ello consideraban necesario tener una población homogénea capaz de sostener el interés de la colectividad. "Bruto" consideraba que en un régimen republicano

${ }^{21}$ "Centinela", "The letter of Centinel", Kenyon, Antifederalists, 1966, p. 11.

${ }_{22}$ "Bruto", "Essay 1", Ketcham, Antifederalist, 1987, p. 275.

${ }^{23} \mathrm{Ibid}$.
1 
las costumbres, sentimientos $e$ intereses del pueblo deben ser similares. De no ser este el caso, habrá un enfrentamiento constante de opiniones, y los representantes de una parte estarán luchando continuamente en contra de los de otras regiones. ${ }^{24}$

James Madison se encargó de rebatir estos puntos. Presentó su defensa de la república extensa en diversas ocasiones. Durante el congreso constituyente de 1787 , sostuvo que enla república extensa, al haber una diversificación de intereses representados, se diseñarian los mecanismos para evitar la tiranía de la mayoría. ${ }^{25} \mathrm{Al}$ enfrentarse a los ataques de los antifederalistas amplió sus argumentos. En el décimo ensayo del Federalista presentó una de las contribuciones más importantes del pensamiento norteamericano a la teoría del republicanismo, al invalidar la noción tradicional de que los mejores beneficios de la representación se obtenían en comunidades pequeñas. ${ }^{26}$ En ese ensayo sostenía que

[elntre más pequeña es la sociedad es menos probable que haya partidos e intereses distintos en ella; entre menos partidos e intereses distintos, será más frecuente que haya una mayoria en el mismo partido [...]. Extended la esfera y habrá una variedad de partidos e intereses; será menos probable que una mayoría del total tenga un motivo común para invadir los derechos de otros principios. ${ }^{27}$

24 "Bruto", ibid., p. 277.

${ }^{25}$ Ferrand, Records, 1937,t. I, p. 136.

${ }^{26}$ Douglass Adair analizó extensamente la influencia de David Hume sobre Madison en "That politics may be reduced to a science': David Hume, James Madison and the tenth federalist", Colboum, Fame, 1974, pp. 93-106.

${ }^{27}$ Hamilton, Madison, Jay, Federalist, 1961, vol. x, p. 83 .
En el esquema de los federalistas, la república extensa ofrecía la solución a uno de los problemas en las democracias directas: la tiranía de la mayoría. La representación era un elemento clave del republicanismo para evitar los peligros del gobierno mayoritario. Madison sostenía que

en la república extendida de Estados Unidos, y entre la gran variedad de intereses, partidos y sectas que incluye, es poco probable que surja una coalición de la mayoría, salvo que lo haga sobre los principios de justicia y de bien común. ${ }^{28}$

Esta defensa de la república extensa ayuda a entender los elementos del republicanismo norteamericano del siglo xvill. Madison definió a la república como "un gobierno que deriva todos sus poderes directa e indirectamente del gran cuerpo popular y es administrada por personas que mantienen sus puestos" durante un periodo limitado o de buen comportamiento. ${ }^{29}$ El elemento de representación era esencial pues según este autor, "la república, por lo que yo entiendo un gobierno en donde tiene lugar el esquema de la representación, abre un prospecto diferente y ofrece una de las curas que estamos buscando". ${ }^{30}$ La representación se convirtió en el medio para permitir el desarrollo de repúblicas en territorios extensos sin basarse en los mecanismos de la democracia directa y evitando sus peligros: es "en la extensión y estructura adecuada de la Unión que tenemos un remedio republicano a los males más incidentes al gobierno republicano". ${ }^{31}$

\footnotetext{
${ }^{28}$ Ibid., vol. L., p. 325.

${ }^{29} \mathrm{Ibid}$., vol. XXXXX, p. 241.

${ }^{30} \mathrm{Ibid}$, vol. $\mathrm{x}, \mathrm{p} .81$.

${ }^{31} \mathrm{Ibid}$., vol. X, p. 84.
} 
Así, esta relación entre representación y republicanismo pasó a ser una de interdependencia mutua, pues la representación es necesaria para asegurar los beneficios de la república extensa; pero la república extensa es necesaria para asegurar los beneficios de la representación. ${ }^{32}$

Madison comprendió las implicaciones de sus propuestas: había revertido las nociones tradicionales del tamaño óptimo de las repúblicas pues argumentó que, entre más grande sea la sociedad, mejor capacidad tendrá para el autogobierno. ${ }^{33}$

Al establecer una relación entre el principio de representación y el tamaño de la república, Madison hizo una contribución sumamente importante a la teoría republicana que pretendía resolver algunos de los dilemas de una comunidad politica de este tipo, y a la vezextensa, a través de la representación. Dentro del esquema madisoniano, las dimensiones del territorio eran un instrumento esencial para permitir que el republicanismo floreciera a lo largo de Estados Unidos. La expansión tenía una utilidad política clara: una república extensa podía garantizar la representación de una diversidad de intereses y, al hacerlo, asegurar los beneficios del republicanismo.

Entre los estudiosos del pensamiento político norteamericano hay consenso acerca de la importancia de la contribución madisoniana. Gordon Wood sostiene que "lo que Madison y los demás federalistas hicieron fue invertir los supuestos del republicanismo para crear y justificar la república federal engrandecida con un nuevo tipo de 'carácter mixto" ${ }^{34}$ Robert J. Morgan ha evaluado

${ }^{32}$ Storing, What, 1981, p. 43.

${ }^{33}$ Hamilton, Madison, Jay, Federalist, 1961, vol. LI, P. 325.

34 Wood, Creation, 1969, p. 504. esta contribución y señala que se trata de una "reversión novedosa de la teoría de que la república tiene que ser pequeña". 35

Los federalistas desarrollaron una respuesta de enormes implicaciones teóricas al invertirel argumento antifederalista de que "la idea de una república sencilla" tan grande como Estados Unidos, con una población de más de 6000000 de habitantes, "todos reducidos al mismo nivel de morales, costumbres y leyes, es en sí mismo un absurdo y es contraria a toda la experiencia de la humanidad". ${ }^{36}$ Anularon los argumentos de que un cuerpo legislativo que representaba una diversidad de intereses, era incapaz de permanecer leal a los principios republicanos. Los federalistas sentaron las bases para un gobierno nacional poderoso en el cual un territorio extenso podía servir al principio de representación y, a la vez, mantener su carácter republicano. Esta propuesta teórica tuvo implicaciones prácticas inmediatas en el proceso de expansión hacia occidente. Madison y los federalistas contemplaban la extensión de los principios republicanos ent territorios más allá de los límites reconocidos de Estados Unidos: "felizmente para la causa republicana, la esfera sobre la cual puede ser aplicable puede abarcar una gran extensión a través de una modificación juiciosa y una mezcla del principio federal". ${ }^{37}$ Inevitablemente, la búsqueda para garantizar los beneficios de la representación a través de una república amplia, acabaría por afectar las relaciones de Estados Unidos con las comunidades vecinas.

\footnotetext{
${ }^{35}$ Morgan, "Madison", 1974, p. 861.

36 "Agripa", "The letters of Agripa", Kenyon, Antifederalists, 1966, p. 134.

${ }^{37}$ Hamilton, Madison, Jay, Federalist, 1961, vol. LI, p. 325.
} 


\section{CONCLUSIÓN}

Durante el periodo de la fundación del Estado nacional norteamericano, el pensamientopolítico dentrodeEstados Unidos experimentó cambios importantes. Los padres fundadores mostraron una gran creatividad, desarrollaron nuevas ideas y modificaron algunos de los supuestos del republicanismo. El caso de Madison es un ejemplo de este proceso, al demostrar que las instituciones representativas podrian garantizar el futuro de una república de grandes dimensiones. Una república que crecía podría proporcionar satisfactores materiales para sus ciudadanos al posibilitar el desarrollo de la economía. Una república amplia podría mantener su carácter y a la vez, aceptar la incorporación de nuevos territorios siempre y cuando se aplicaran principios republicanos sobre ellos. Esta forma de gobierno podría crecer si a la vez se daba una extensión del republicanismo.

Quienes apoyaron la Constitución de 1787 tuvieron que demostrar a sus compatriotas que la república extensa era una posibilidad teórica cuando ya de hecho se había convertido en una realidad. El proceso de demostración invalidó algunas de las principales objeciones de los antifederalistas y el supuesto de que una república de amplias dimensiones territoriales perdería su carácter y eventualmente entraría a un proceso de degeneración. Desde la perspectiva del pensamiento político, ésta fue una de las principales contribuciones de autores como James Madison; el tema de la expansión se convirtió en una parte íntegra del pensamiento político norteamericano y sobre todo del pensamiento republicano de ese país.
La expansión tuvo una dimensión política durante el periodo de la fundación. Por una parte se vinculó con la generación de condiciones que permitirían la proliferación del republicanismo. Dentro del esquema madisoniano, implicóla incorporación de nuevos intereses a ser representados: la base fisica que permitiría una diversificación de intereses sería una república extensa que crecía. En términos regionales, la expansión hacia el occidente se vinculó con el desarrollo de la esclavitud o la agricultura de mano de obra libre, y en términos sectoriales, planteaba la necesidad de definir políticas gubernamentales para promover a la agricultura, la industria oel comercio. Los postulados clásicos de pensadores y teóricos del republicanismo con respecto a la expansión adquirieron un nuevo sentido en el caso de EU.

En sintesis, los temas de la expansión y del tamaño ideal de la república, permiten avanzar en el conocimiento del pensamiento republicano de Estados Unidos y además, entender su especificidad. Ambos temas se desarrollaron en un contexto específico durante el periodo de la fundación, razón por la cual adquirieron un sentido particular. A su vez, se convirtieron en elementos centrales para determinar la orientación de las relaciones de Estados Unidos con sus comunidades vecinas. Las consideraciones con respecto al crecimiento y la diversificación de intereses tendrían una incidencia directa sobre el proceso de expansión territorial hacia el occidente. Si bien una vez entrado el siglo XIX; otras consideraciones pasaron a ocupar un lugar preeminente, la búsqueda de soluciones propias para los retos del republicanismo fue uno de los motores de la primera fase de la expansión territorial de Estados Unidos. 


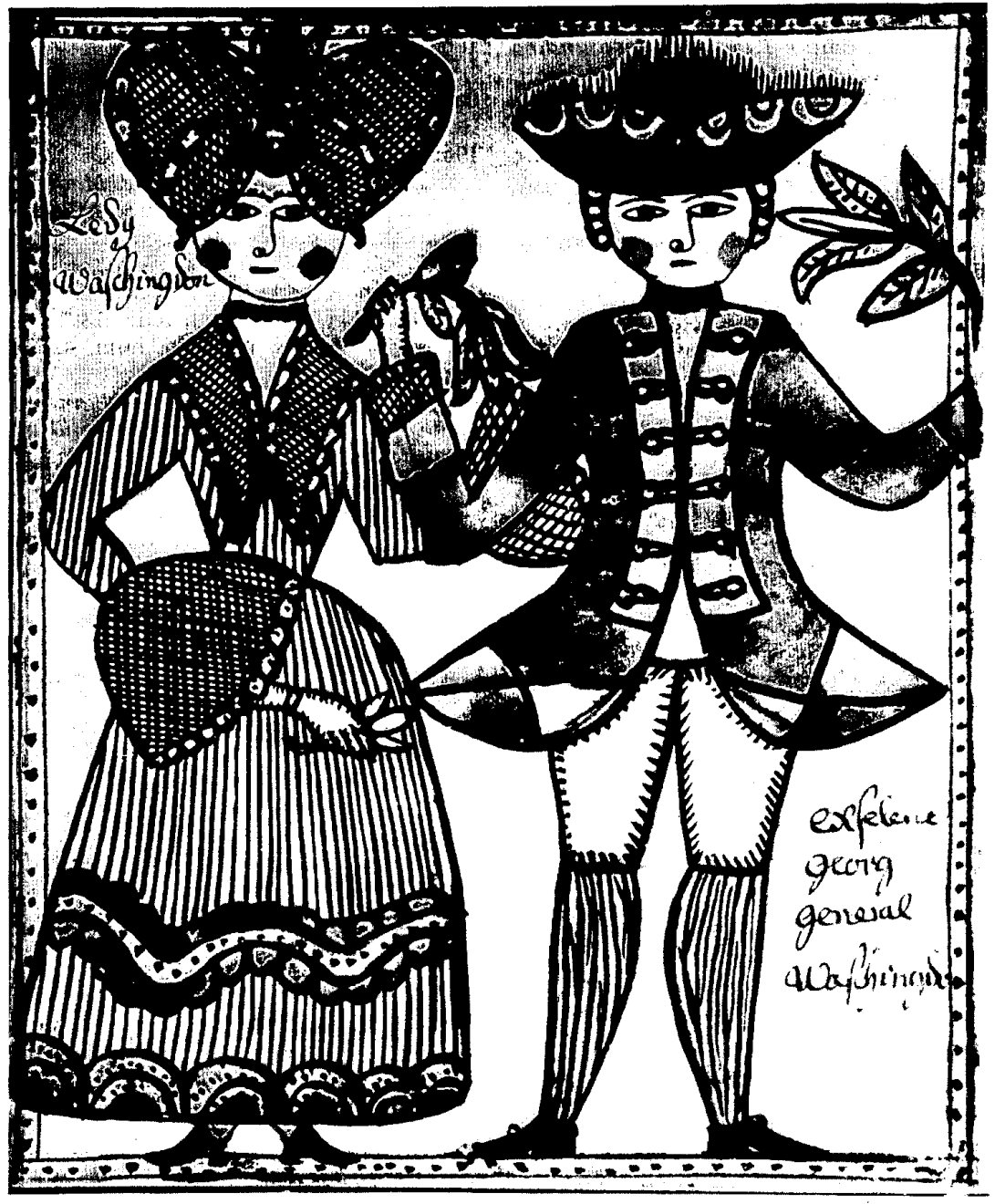


BibLIOGRAFIA

-Adair, Douglass, "'That politics may be reduced to a science': David Hume, James Madison and the tenth federalist", Trevor Colbourn (comp.), Fame and the founding fathers: essays by Douglass Adair, Norton, Nueva York, 1974.

-Appleby, Joyce, "Republicanism in the old and new contexts", The William and Mary Quarterly, vol. xuli, núm. 1, enero de 1986, pp. 20-34.

-Bailyn, Bernard, The ideological origins of the american revolution, Harvard University Press, Cambridge, 1967.

-Commanger, Henry Steele, Documents of atnerican bistory, Appeton-Century-Crofts, Nueva York, 1973.

-Ferrand, Max (comp.), The records of the federal convention of 1789 , Yale University Press, New Haven, 1937, t. I.

-Hamilton, Alexander, James Madison, John Jay, The Federalist Papers, Clinton Rossiter (comp.), Mentor, Nueva York, 1961.

-Hartz, Louis, The liberal tradition in America: an interpretation of american political thought since the revolution, Harcourt, Brace y World, Nueva York, 1955.

-Jefferson, Thomas, Basic writings of ThomasJefferson, PhilipS. Forner (comp.), Willey, Nueva York, 1944.

-Kenyon, Cecilia (comp.), The antifederalist, Bobbs Merril, Indianápolis, 1966.

-Ketcham, Ralph (comp.), The antifederalist papers and the constitutional convention debates, Mentor, Nueva York, 1987.
-Kramnick, Issac, The American Historical Review, vol. Lxxxvi, núm. 2, junio 1982, pp. 629-664.

-Madison, James, Letters and other writings of James Madison, Lippincot, Filadelfia, 1865.

Papers of James Madison, compilación de Robert Rutland y Charles Hobson, of Virginia Press, Charlottesville, 1962. t. xI.

The papers of James Madison, William T. Hutchinson y William M. E. Rachal (comps.), University of Chicago Press, Chicago, 1962.

-Morgan, Robert J., "Madison's theory of representation in the tenth federalist", The Jourmal of Politics, vol. xxvi, núm. 4, noviembre de 1974 .

-Pocock, J.G.A., The macbiavellian moment: florentine political thought and the Atlantic republican tradition, Princeton University Press, Princeton, 1975.

-Ross, Dorothy, "The liberal tradition revisited and the republican tradition addressed", John Highman y Paul K. Conkin (comps.), New directors in american intellectual bistory, Johns Hopkins University Press, Baltimore, 1979.

-Storing, Herbert, What the anti-federalist were for: the political thought of the opponents of the constitution, The University of Chicago Press, Chicago, 1981.

-Wood, Gordon, The creation of the american republic, 1776-1 787, University of North Carolina Press, Chapel Hill, 1969. 